\title{
EDUKASI GIZI BAGI PASIEN DIABETES MELLITUS TIPE 2 DI PUSKESMAS KAHURIPAN KOTA TASIKMALAYA
}

\author{
Tri Kusuma Agung Puruhita ${ }^{1}$, Naning Hadiningsih ${ }^{2}$ \\ ${ }^{1}$ Prodi D3 Gizi Tasikmalaya, Jurusan Gizi Poltekkes Tasikmalaya \\ ${ }^{2}$ Prodi D3 Gizi Tasikmalaya, Jurusan Gizi Poltekkes Tasikmalaya
}

agungpuruhita@gmail.com

Diterima: 30 Oktober 2018

Direvisi: 17 November 2018

Diterbitkan: 07 Januari 2019

\begin{abstract}
The prevalence of DMT-2 in Indonesia is known to have increased from $1.1 \%$ in 2007 to $2.1 \%$ in 2013. One of the pillars of managing diabetes mellitus is the application of medical nutrition therapy, which consists of providing diet regulation, counseling, and behavior modification. Kahuripan Community Health Center is the first level health care facility that manages Prolanis (Chronic Disease Management Program) for patients with Diabetes Mellitus (DMT-2) and Hypertension. There were 30 DMT-2 patients who attended education on Thursday 3rd week. The number, type, and schedule (3J) of carbohydrate intake is the main determinant fot post-prandial blood glucose levels increase. Understanding and implementation of $3 \mathrm{~J}$ in DMT-2 patients is still inadequate. Education is carried out using a media food model and a food photo book so that the description of the food portion is more appropriate. Patients and families are given knowledge about the calculation of the number of carbohydrates (carbohydrate counting basic) in order to be able to choose food ingredients according to the number and portion. Physical activity selected several activities that can be done at home, according to the age characteristics of patients who are mostly elderly. Counseling, carbohydrate counting education, and physical activity strategy can improve patient knowledge, but not all patients are willing and able to implement the results of education. There were two respondents who had pre and post counseling blood glucose levels experienced a decline, because they had started to apply $3 \mathrm{~J}$ changes and physical activity.
\end{abstract}

\begin{abstract}
ABSTRAK
Prevalensi DMT-2 di Indonesia diketahui mengalami peningkatan dari 1,1\% pada tahun 2007 menjadi $2,1 \%$ pada tahun 2013. Salah satu pilar penatalaksanaan penyakit diabetes mellitus yaitu dengan penerapan terapi gizi medis, terdiri dari pemberian pengaturan makanan, konseling terhadap pasien, dan modifikasi perilaku. Puskesmas Kahuripan merupakan fasilitas pelayanan kesehatan tingkat pertama yang mengelola Prolanis (program pengelolaan penyakit kronis) bagi pasien Diabetes Mellitus (DMT-2) dan Hipertensi. Terdapat 30 orang pasien DMT-2 yang mengikuti edukasi pada hari kamis minggu ke-3. Jumlah, jenis, dan jadwal (3J) asupan karbohidrat merupakan determinan utama penyebab kenaikan kadar glukosa darah post prandial, pemahaman dan pelaksanaan 3J pada pasien DMT-2 masih belum memadai. Edukasi penukar dilakukan menggunakan media food model dan buku foto makanan sehingga gambaran porsi makanan yang lebih tepat. Pasien dan keluarga diberikan pengetahuan mengenai perhitungan jumlah karbohidrat (carbohydrate counting basic) agar mampu memilih bahan makanan sesuai jumlah dan porsi. Aktivitas fisik dipilih beberapa kegiatan yang dapat dilakukan di rumah, sesuai dengan karakteristik umur pasien yang sebagian besar telah lansia. Pemberian konseling, edukasi carbohydrate counting, serta aktivitas fisik dapat meningkatkan
\end{abstract}


pengetahuan pasien, meskipun demikian belum semua pasien mau dan mampu menerapkan hasil edukasi. Terdapat dua responden yang memiliki kadar glukosa darah pre dan post konseling mengalami penurunan, karena sudah mulai menerapkan perubahan $3 \mathrm{~J}$ dan aktivitas fisik.

\section{Kata Kunci $\quad$ : DMT2, Prolanis, Konseling, Aktifitas Fisik, Foto Makanan}

\section{PENDAHULUAN}

Diabetes melitus merupakan kumpulan gejala yang timbul pada seseorang ditandai dengan peningkatan kadar glukosa darah post prondial maupun glukosa darah puasa sebagai akibat kurangnya produksi insulin maupun terjadinya resistensi insulin (Al-Mahmood et al. 2011). Prevalensi diabetes mellitus di Indonesia diketahui mengalami peningkatan dari 1,1\% pada tahun 2007 menjadi 2,1\% pada tahun 2013 (Kementerian Kesehatan RI 2013). Salah satu pilar penatalaksanaan penyakit diabetes mellitus yaitu dengan penerapan terapi gizi medis. Terapi gizi medis merupakan manajemen asuhan gizi pasien dengan melibatkan pemberian pengaturan makanan, konseling terhadap pasien, dan modifikasi perilaku (Franz 2007). Terapi gizi medis merupakan manajemen asuhan penyakit kepada pasien yang meliputi langkah - langkah diagnose gizi (nutritional diagnostic), terapi gizi, dan konseling gizi yang dilaksanakan oleh seorang registered dietitian (RD) (Morris \& Wylie-Rosset 2010). Banister et al. (2004), menyebutkan edukasi selama 2 - 12 bulan dapat memperbaiki nilai $\mathrm{HbA} 1_{\mathrm{C}}$ sebanyak $15 \%$ pada 70 orang response DMT2. Aktivitas fisik dapat menurunkan resistensi insulin dan glukosa darah. Jika dilakukan secara regular dapat mencegah kenaikan berat badan dan memiliki peran penting terhadap penurunan berat badan. Olahraga aerobic dapat meningkatkan respon insulin sehingga meningkatkan pengambilan glukosa darah ke dalam sel, sedangkan olahraga daya tahan dapat meningkatkan kekuatan otot, menurunkan keseimbangan energy sehingga menstimulasi penurunan berat badan (Ebrahimof \& Mirmiran 2013). Puskesmas Kahuripan merupakan salah satu Puskesmas yang berada di bawah pembinaan Dinas Kesehatan Kota Tasikmalaya, salah satu programnya adalah pelaksanaan Prolanis. Terdapat 30 orang pasien DMT2 yang mengikuti program edukasi pada hari kamis minggu ke-3 (DMT2). Selain edukasi gizi, juga dilakukan senam prolanis pada sabtu minggu ke-1 dan minggu ke-3. Jumlah, jenis, dan jadwal asupan karbohidrat merupakan determinan utama yang menyebabkan kenaikan kadar glukosa darah post prandial (Franz et al. 2010). Porsi makan mempengaruhi banyak jumlah karbohidrat tersedia (available carbohydrat) yang dikonsumsi. Salah satu metode untuk mengatur porsi makan adalah dengan melakukan edukasi besarnya penukar dengan menggunakan media food model atau food sample. Strategi lain yang dapat digunakan adalah dengan menggunakan buku foto makanan atau gambar ilustrasi yang disertai dengan skala, sehingga dapat memberikan gambaran porsi makanan yang lebih tepat. Foto makanan digital bermanfaat sebagai media untuk membantu ingatan selama proses recall 24 jam dan sebagai alat untuk estimasi porsi makanan (Lazarte et al. 2012).

Kegiatan yang dilakukan pada pengabdian masyarakat ini didahului dengan melakukan edukasi pengetahuan gizi, terutama jadwal, jenis, dan jumlah (3J) asupan sumber karbihidrat. Edukasi tahap kedua dilakukan dengan melakukan konseling gizi home visit kepada pasien untuk memastikan terjadi perubahan perilaku. Edukasi tahap ketiga dilakukan dengan cara memberikan strategi aktivitas fisik yang dapat dilakukan oleh pasien di lingkungan tempat tinggal masing - masing.

\section{METODE}

Pelaksanaan kegiatan Pengabdian kepada Masyarakat dilaksanakan mulai bulan Februari 2018 sampai dengan bulan September 2018. Bertempat di Puskesmas Kahuripan Kota Tasikmalaya dan rumah responden. Khalayak sasaran dalam kegiatan Pengabdian kepada Masyarakat ini adalah pasien 
penderita Diabetes Mellitus Tipe 2 yang menjadi peserta Prolanis Puskesmas Kahuripan Kecamatan Tawang Kota Tasikmalaya, sebanyak 22 orang. Kegiatan ini merupakan pemberian edukasi bagi penderita DMT2 agar memahami konsep pengaturan makanan 3J (jadwal, jenis, jumlah) sehingga mampu mengatur dan memilih bahan makanan yang dapat membantu mengatur kestabilan glukosa darah. Konseling dan asuhan gizi dilakukan pada waktu yang bersamaan untuk mendapatkan informasi terkait masalah gizi yang dihadapi pasien, diagnosa gizi dan intervensi berupa pemberian personal diet sesuai dengan masalah, serta evaluasi dalam waktu yang disepakati. Kegiatan konseling edukasi secara personal kepada pasien DMT2 bertujuan untuk memberikan motivasi, kesadaran untuk perubahan perilaku, serta kemandirian dalam melaksanakan asuhan gizi. Monitoring glukosa darah puasa dan 2 jam post prandial dilakukan untuk mengetahui perubahan pra dan post konseling. Pemberian edukasi strategi aktivitas fisik berupa pedoman kegiatan aktivitas fisik dalam bentuk gambar gerakan - gerakan yang tepat bagi pasien DMT2 untuk dilakukan rumah masing-masing agar mampu membantu mengontrol glukosa darah.

\section{HASIL DAN PEMBAHASAN}

Konseling dan Asuhan Gizi kepada pasien dilakukan di rumah pasien (home visit). Pada kegiatan ini hanya 16 orang pasien yang dapat dikonseling. Sebanyak 1 orang tidak dapat dikonseling karena alasan lokasi rumah yang terletak di luar kota tasikmalaya, dan sisanya 5 orang karena tidak dapat dihubungi pada saat akan dilakukan home visit. Karakteristik 16 orang pasien yang mengikuti konseling disajikan pada Tabel 2.

Hasil evaluasi dari proses konseling menunjukkan $100 \%$ pasien tidak mengetahui jadwal, jenis, dan jumlah makanan yang harus dikonsumsi, serta tidak mampu mengatur porsi makanan. Pemberian konseling disertai dengan materi perhitungan karbohidrat (carbohydrate counting) kepada pasien dan keluarga mampu merubah perilaku pasien dan pola makan. Pada saat proses konseling diberikan contoh foto - foto beberapa porsi makanan, standar penukar, dan ukuran rumah tangga nya.

Terdapat dua responden yang konsisten mengikti petunjuk diet, sehingga pada pengukuran glukosa darah post konseling memiliki kadar glukosa darah yang lebih rendah dibandingkan pada pre konseling, data kadar glukosa darah dilampirkan pada Tabel 2.

Tabel 1. Karakteristik Responden Yang Mengikuti

Konseling

\begin{tabular}{|ccc|}
\hline $\begin{array}{c}\text { Karakteristik } \\
\text { Range Umur }\end{array}$ & Jumlah & \% \\
$>\mathbf{7 0}$ & 2 & 12,5 \\
$\mathbf{6 0}-\mathbf{7 0}$ & 4 & 25 \\
$\mathbf{5 0}-\mathbf{6 0}$ & 8 & 50 \\
$\mathbf{4 0}-\mathbf{5 0}$ & 2 & 12,5 \\
& & \\
Jenis Kelamin & & \\
Laki laki & 6 & 37,5 \\
Perempuan & 10 & 62,5 \\
& & \\
\hline
\end{tabular}


Tabel 2. Glukosa darah Responden Pre dan Post Konseling

\begin{tabular}{|c|c|c|c|c|c|}
\hline \multirow[t]{3}{*}{ No } & \multirow[t]{3}{*}{ Nama } & \multicolumn{2}{|l|}{ Pre } & \multicolumn{2}{|l|}{ Post } \\
\hline & & GD & GD2JPP & GD & GD2JPP \\
\hline & & \multicolumn{2}{|c|}{$\mathrm{P}$} & \multicolumn{2}{|c|}{$\mathrm{P}$} \\
\hline \multirow[t]{2}{*}{1} & Adawiyah & 12 & 141 & 125 & 145 \\
\hline & & 2 & & & \\
\hline \multirow[t]{2}{*}{2} & Iman Sutardji & 10 & 107 & 97 & 110 \\
\hline & & 0 & & & \\
\hline \multirow[t]{2}{*}{3} & Sri Widaryati & 10 & 107 & 147 & 203 \\
\hline & & 0 & \multicolumn{2}{|c|}{,2 } & \\
\hline 4 & Yahya & - & 392 & - & - \\
\hline \multirow[t]{2}{*}{5} & Dede sulaeman & 11 & 137 & 170 & 220 \\
\hline & & 2 & & & \\
\hline \multirow[t]{2}{*}{6} & Ai Idah & 20 & 218 & 153 & 162 \\
\hline & & 0 & & & \\
\hline \multirow[t]{2}{*}{7} & Euis Heryani & 15 & 225 & - & - \\
\hline & & 0 & & & \\
\hline \multirow[t]{2}{*}{8} & Lela Nurlela & 15 & 128 & 196 & 204 \\
\hline & & 6 & & & \\
\hline \multirow[t]{2}{*}{9} & Mahrodin & 14 & 248 & 127 & 123 \\
\hline & & 5 & & & \\
\hline 1 & Euis Heryani & 65 & 265 & 65 & 120 \\
\hline \multicolumn{6}{|l|}{$\mathbf{0}$} \\
\hline 1 & Ilah Karmilah & 21 & 222 & 205 & 290 \\
\hline 1 & & 5 & & & \\
\hline $\mathbf{1}$ & Maryani & 15 & 152 & - & - \\
\hline \multicolumn{2}{|l|}{2} & 6 & & & \\
\hline 1 & Rustijah & 13 & 237 & - & - \\
\hline \multicolumn{2}{|l|}{3} & 5 & & & \\
\hline 1 & Ucu Marliana & 17 & 249 & 200 & - \\
\hline \multicolumn{2}{|l|}{4} & 0 & & & \\
\hline 1 & Hasyim & 95 & 98 & 95 & 140 \\
\hline \multicolumn{6}{|l|}{5} \\
\hline 1 & Tedi Sumantri & 90 & 210 & 113 & 101 \\
\hline \multicolumn{6}{|l|}{6} \\
\hline
\end{tabular}

\section{BAB V. SIMPULAN}

Penyuluhan mampu meningkatkan pengetahuan pasien, tetapi belum mampu merubah perilaku pasien. Konseling kepada pasien dan keluarga dengan memberikan contoh foto makanan, porsi makanan, dan carbohydrate counting memberikan pemahaman yang baik, dan diharapkan dapat merubah pola makan pasien. Aktifitas fisik memberikan pemahaman mengenai peran pengambilan glukosa darah oleh otot, selain itu dapat meningkatkan fleksibiltas anggota tubuh. 


\section{DAFTAR PUSTAKA}

1. Al-Mahmood, A.K., Afrin, S.F. \& Hoque, N., 2011. Metabolic Syndrome and Insulin resistance: Etiopathegenesis and Influencing Factors. Bangladesh Journal of Medical Biochemistry, 4(2), pp.26-31.

2. Banister, N.A. et al., 2004. Diabetes Self-Management Training Program in a Community Clinic Improves Patient Outcomes at Modest Cost. Journal of The Academy of Nutrition and Dietetics, 104(5), pp.807-810.

3. Ebrahimof, S. \& Mirmiran, P., 2013. Nutritional Approaches for Prevantion and Treatment of Metabolic Syndrome in Adults. Journal of Paramedical Sciences (JPS), 4(2), pp.123-134.

4. Franz, M.J. et al., 2010. The evidence for medical nutrition therapy for type 1 and type 2 diabetes in adults. Journal of the American Dietetic Association, 110(12), pp.1852-89. Available at: http://www.sciencedirect.com/science/article/pii/S0002822310014902.

5. Franz, M.J., 2007. The Role of Nutrition Therapy and Dietitians in the Management of the Metabolic Syndrome. Current Diabetes Reports, 7, pp.60-65.

6. Kementerian Kesehatan RI, 2013. Riset Kesehatan Dasar.

7. Lazarte, C.E. et al., 2012. Validation of Digital Photographs, as a Tool in 24-H Recall, For The Improvement of Dietary Assessment Among Rural Populations in Developing Countries. Nutrition Journal, 11(1), p.61. Available at: http://nutritionj.biomedcentral.com/articles/10.1186/1475-2891-11-61.

8. Di Loreto, C. et al., 2003. Validation of a Counseling Strategy to Promote the Adoption and the Maintenance of Physical Activity by Type 2 Diabetic Subjects. Diabetes Care, 26(2), pp.404408. Available at: http://care.diabetesjournals.org/content/26/2/404.

9. Morris, S.F. \& Wylie-Rosset, J., 2010. Medical Nutrition Therapy: A Key to Diabetes Management and Prevention. Clinical Diabetes, 1. Available at: http://www.ncbi.nlm.nih.gov/pubmed/12566502.

10. Puruhita, T.K.A. \& Hidayat, A.A.S., 2017. Pengujian Indeks Glikemik Cookies Diabetes Formula Tepung Sorghum (Sorghum bicolor) dan Kacang Merah Pratanak (Paseolus vulgaris) Pada Penderita Diabetes Mellitus Tipe 2, Tasikmalaya.

11. Sitompul, S., Suryawati, C. \& Wigati, P.A., 2016. Analisis Pelaksanaan Program Penyakit kronis (Prolanis) BPJS Kesehatan Pada Dokter keluarga di Kabupaten Pekaloongan tahun 2016. Jurnal Kesehatan Masyarakat, 4(4), pp.145-153.

12. Soelistijo, S.A. et al., 2015. Konsensus Pengelolaan Dan Pencegahan Diabetes Melitus Tipe 2 Di Indonesia, PB. Perkeni. 